\title{
Five-year survival does not equal cure in non-small cell lung cancer: A Surveillance, Epidemiology, and End Results-based analysis of variables affecting 10- to 18-year survival
}

\author{
Matthew O. Hubbard, MD, ${ }^{\mathrm{a}, \mathrm{b}}$ Pingfu Fu, PhD, ${ }^{\mathrm{c}}$ Seunghee Margevicius, MA, ${ }^{\mathrm{c}}$ Afshin Dowlati, MD, ${ }^{\mathrm{a}, \mathrm{d}}$ and \\ Philip A. Linden, MD ${ }^{\mathrm{a}, \mathrm{b}}$
}

\begin{abstract}
Objective: Five-year survival after the diagnosis of non-small cell lung cancer is the most common benchmark used to evaluate long-term survival. Data on survival beyond 5 years are sparse. We sought to elucidate variables affecting 10- to 18 -year survival.
\end{abstract}

\begin{abstract}
Methods: A total of 31,206 patients alive at least 5 years after diagnosis of non-small cell lung cancer who were registered in the Surveillance, Epidemiology, and End Results database from 1988 to 2001 were examined. Primary end points were disease-specific survival and overall survival. Survival analysis was performed with Kaplan-Meier estimates, multivariable Cox proportional hazards regression, and competing risk models.
\end{abstract}

\begin{abstract}
Results: Overall survival at 10,15, and 18 years was $55.4 \%, 33.1 \%$, and $24.3 \%$, respectively. Disease-specific survival at 10,15 , and 18 years was $76.6 \%, 65.4 \%$, and $59.4 \%$, respectively. In multivariable regression analysis, squamous cell cancers had a disease-specific survival advantage (hazard ratio, $0.88 ; P<.0001$ ) but an overall survival disadvantage (hazard ratio, 1.082; $P=.0002$ ) compared with adenocarcinoma. Pneumonectomy (hazard ratio, 0.44) and lobectomy (hazard ratio, 0.474) had improved disease-specific survival compared with no surgery $(P<.0001)$. Left-sided tumors (hazard ratio, 0.723; $P=.036)$ and node-negative cancers (hazard ratio, $0.562 ; P<.001)$ also had a better disease-specific survival and, to a lesser extent, overall survival advantage.
\end{abstract}

Conclusions: Five-year survivors of non-small cell lung cancer have a persistent risk of death from lung cancer up to 18 years from diagnosis. More than one half of all deaths in 5-year survivors are related to lung cancer. In multivariable regression analysis, age, node-negative disease, and lobar or greater resection were strong predictors of long-term survival (ie, 10-18 years). (J Thorac Cardiovasc Surg 2012;143:1307-13)

Non-small cell lung cancer (NSCLC) is one of the most common noncutaneous cancers, with more than 222,520 new cases in $2010 .{ }^{1}$ Only $15 \%$ of patients with newly diagnosed lung cancer will be expected to survive 5 years from their diagnosis. ${ }^{2}$ Five-year survival is the most commonly used benchmark for long-term survival in NSCLC and has, at times, been equated with cure. ${ }^{3}$ Others have claimed that 5 years is inadequate and have proposed 10 years as "adequate proof of cure." 4 Prospective long-term cancer studies are costly, and data beyond 5 years are scarce.

Prior studies have suggested equivalent 5- and 10-year survivals. The International Early Lung Cancer Screening Program involving approximately 30,000 screened patients

\footnotetext{
From the Case Western Reserve School of Medicine, ${ }^{\mathrm{a}}$ Division of Thoracic and Esophageal Surgery, ${ }^{\mathrm{b}}$ University Hospitals-Case Medical Center, Cleveland, Ohio; Department of Epidemiology and Biostatistics, ${ }^{c}$ Case Western Reserve School of Medicine, and Division of Hematology and Oncology, ${ }^{\mathrm{d}}$ University Hospitals-Case Medical Center, Cleveland, Ohio.

Disclosures: Authors have nothing to disclose with regard to commercial support.

Received for publication July 18, 2011; revisions received Jan 17, 2012; accepted for publication Jan 25, 2012; available ahead of print Feb 23, 2012.

Address for reprints: Philip A. Linden, MD, Division of Thoracic and Esophageal Surgery, University Hospitals Case Medical Center, 11100 Euclid Avenue, Cleveland, OH 44124 (E-mail: philip.linden@uhhospitals.org). $0022-5223 / \$ 36.00$

Copyright (c) 2012 by The American Association for Thoracic Surgery doi:10.1016/j.jtcvs.2012.01.078
}

and 484 patients with lung cancer showed that the estimated 5- and 10-year survivals were nearly identical in this group of mostly patients with stage I lung cancer. ${ }^{5}$ This screened population was obviously a highly selected group with early lung cancers. In 1999, a report from Memorial Sloan Kettering reviewed 686 long-term survivors who had undergone curative resection between 1973 and 1989. The estimated overall 10 -year survival was $93 \%$ for patients with stage I lung cancer and $92 \%$ for patients with stage II and III lung caner. In this study of 686 patients, however, no variables (including age, sex, histology, or stage) were useful in predicting late recurrence. ${ }^{6}$

We sought to examine long-term survival in NSCLC using the Surveillance, Epidemiology, and End Results (SEER) database of the National Cancer Institute. This database represents a cross-section of socioeconomic and geographic populations across the United States and allows for analysis of individual variables, stage, and treatment factors on long-term survival. We sought to further clarify longterm survival and examine variables affecting 10-, 15-, and 18-year survival.

\section{MATERIALS AND METHODS}

The study population was patients with NSCLC from the SEER database of the National Cancer Institute from 1988 to 2001 with follow-up 


$$
\begin{aligned}
& \text { Abbreviations and Acronyms } \\
& \begin{aligned}
\text { DSS } & =\text { disease-specific survival } \\
\text { HR } & =\text { hazard ratio } \\
\text { NSCLC } & =\text { non-small cell lung cancer } \\
\text { OS } & =\text { overall survival } \\
\text { SEER } & =\text { Surveillance, Epidemiology, and End } \\
& \text { Results }
\end{aligned}
\end{aligned}
$$

of at least 5 years (through 2006 at the latest). The SEER database is a multi-institutional, community-based cancer registry from 12 population-based cancer registries in the United States, containing demographics, clinical, pathologic, and survival data. An exemption for institutional review board review and need for individual patient consent was granted by the Case Western Institutional Review Board, ExemptCC010-2008.

Data regarding patient age, year of diagnosis, patient gender and race, tumor side, histology, size, nodal involvement, regional and distant extension/metastases, stage, overall survival (OS) (in months), and cause of death were collected. Tumor size was categorized as less than $3 \mathrm{~cm}$ or greater than or equal to $3 \mathrm{~cm}$ for univariate analysis.

The age of the patient was collected at the time of diagnosis or initial treatment. The histology of tumors was classified into 6 categories based on the International Classification of Diseases for Oncology ${ }^{7}$ : squamous cell carcinomas (8050-8123, 8562), adenocarcinomas (8140, 8141, 8250-8323, 8480-8550, 8572), large cell carcinomas (8012-8031), adenosquamous carcinomas $(8560,8570)$, unknown histology $(8000,8010$, and missing values), and other tumors that includes spindle-cell carcinomas, mucoepidermoid malignancies, and carcinoid tumors. Surgery type was categorized as pneumonectomy, lobectomy (with or without nodal dissection), sublobectomy resection (wedge resection or segmentectomy), or no surgery. Excisional biopsies and other surgeries performed without curative intent were categorized in the "no surgery" group.
A total of 51,072 patients aged more than 18 years who had survived 60 months or more diagnosed with NSCLC were located. A total of 34,572 patients were diagnosed on or after 1988. A total of 34,510 patients remained after the exclusion of in situ disease. A total of 31,206 patients remained for analysis after exclusion of those patients for whom type of surgery or absence of surgery was not documented.

Patients alive (including those with disease) at least 5 years after diagnosis were included. Cause of death was determined by the SEER database collection of hospital and death certificate information and stated using the International Classification of Diseases, 10th Revision. ${ }^{8}$ OS was measured from the date of diagnosis to the date of death and censored at the date of last follow-up for survivors. Disease-specific survival (DSS) was measured from the date of diagnosis to the date of death from lung cancer and censored at the date of last follow-up for survivors or the date a patient died of causes other than lung cancer. The determination of a lung cancer versus non-lung cancer cause of death was determined in order of availability by state health department records, other sources such as the National Death Index or state data exchange, and coding from a trained International Classification of Diseases, 10th Revision expert for registry data entry.

Probability of OS and DSS was estimated using the Kaplan-Meier method for categoric variables in the univariate analysis; the difference between/among groups was examined using the log-rank test. The factors that were significant in predicting OS and DSS in the univariate analysis were further examined by Cox proportional hazard regression ${ }^{9}$ and competing risk models, ${ }^{10,11}$ respectively. Multivariable regression models that include the variables of age (in years), gender, histology, tumor site, TNM status, and surgery type performed were done for OS and DSS. All tests were 2-sided. Significant differences in DSS and OS for different T and $\mathrm{N}$ status in the univariate analysis were determined by the log-rank

\begin{tabular}{|c|c|c|c|}
\hline Factor & $\mathbf{N}(\%)$ & Factor & $\mathbf{N}(\%)$ \\
\hline Male & $15,118(48.45)$ & Side of tumor & \\
\hline Histology & & 0 (not paired site) & $5(0.02)$ \\
\hline Adeno & $15,876(50.87)$ & 1 (right) & $18,004(57.69)$ \\
\hline Adenosquamous & $716(2.29)$ & 2 (left) & $12,936(41.45)$ \\
\hline Large cell & $1980(6.34)$ & 3 (only 1 side) & $29(0.09)$ \\
\hline Other & $2373(7.60)$ & 4 (bilateral) & $93(0.30)$ \\
\hline Squamous & 8098 (25.95) & 9 (paired site) & $139(0.45)$ \\
\hline Unknown & $2163(6.93)$ & Surgery type & \\
\hline Stage & & Lobectomy & $21,423(68.65)$ \\
\hline IA/IB & $11,030 / 10,659(69.50)$ & No surgery & 4679 (14.99) \\
\hline IIA/IIB & $829 / 775(5.14)$ & Pneumonectomy & $2203(7.06)$ \\
\hline IIIA/IIIB & $2210 / 4206(20.56)$ & Sublobectomy & $2901(9.30)$ \\
\hline IV & $1497(4.80)$ & Race & \\
\hline T stage & & White & $26,601(85.24)$ \\
\hline $\mathrm{T} 1$ & $12,985(41.61)$ & Black & $2668(8.55)$ \\
\hline $\mathrm{T} 2$ & $14,352(45.99)$ & Other & $1937(6.21)$ \\
\hline $\mathrm{T} 3$ & $1157(3.71)$ & $\mathrm{N}$ stage & \\
\hline $\mathrm{T} 4$ & $2146(6.88)$ & No & $23,847(76.42)$ \\
\hline Unknown & $566(1.81)$ & N1 & $3178(10.18)$ \\
\hline M stage & & $\mathrm{N} 2$ & $2924(9.37)$ \\
\hline M0 & $29,709(95.20)$ & N3 & $415(1.33)$ \\
\hline M1 & $1497(4.80)$ & Unknown & $842(2.70)$ \\
\hline
\end{tabular}
test followed by the Tukey method for multiple comparisons.

\section{RESULTS}

A total of 31,206 patients met the inclusion criteria for this study with a median age of 66 years (range, 18-103 years). The patient and cancer characteristics at diagnosis

TABLE 1. Patient and cancer characteristics at diagnosis or initial treatment 


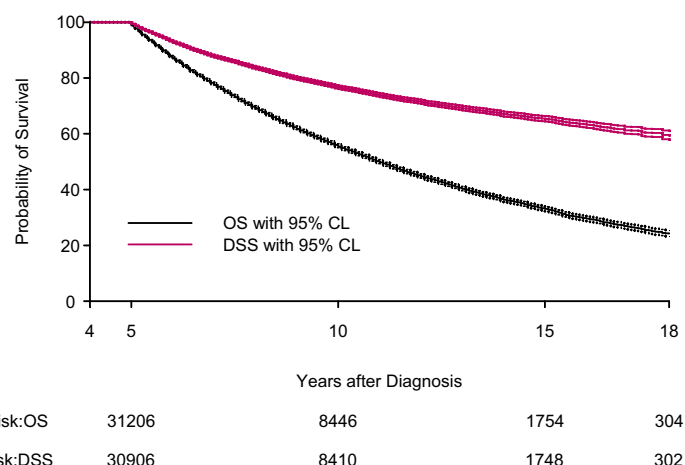

FIGURE 1. Graphs of DSS (top red line) and OS (bottom black line) in patients with NSCLC surviving more than 5 years. $C L$, Confidence limit; $D S S$, disease-specific survival; $O S$, overall survival.

or initial treatment are summarized in Table 1 . Seventy patients $(69.5 \%)$ had stage IA/IB disease. Surgery was performed on most patients; 4679 patients $(15 \%$ of the cohort) had no curative surgery attempted. OS and DSS curves are shown in Figure 1.

OS data analysis by the Kaplan-Meier method for single variables is shown in Table 2. Data are shown for survival at 10,15 , and 18 years (the longest survival possible given the data range of 1988-2006) from the time of diagnosis. The entire group of 31,206 patients had $55.4 \%$ survival at 10 years, $33.1 \%$ survival at 15 years, and $24.3 \%$ survival at 18 years. Significant differences can be seen in OS according to age, gender, tumor size, nodal status, presence of metastatic disease, tumor side, histology, stage, and type of curative surgery. The results from multivariable Cox proportional hazard for OS are detailed in Table 3. The differences between $\mathrm{T} 2$ and $\mathrm{T} 3$ and $\mathrm{T} 2$ and $\mathrm{T} 4$ were not statistically significant $(P>.05)$. Nodal stage had a significant impact on OS: The hazard ratio (HR) was 1.325 for N1 versus N0, 1.254 for $\mathrm{N} 2$ versus $\mathrm{N} 0$, and 1.116 for $\mathrm{N} 3$ versus N0. Moreover, there were statistically significant differences in OS between each pair of nodal stage (ie, N1 vs $\mathrm{N} 2$, N1 vs N3, and N2 vs N3) (with a multiple comparisons adjusted $P<.004$ ).

For DSS, 300 patients were excluded because there was no cause of death listed in the database. Patients who were alive at the time of censoring or the end of data collection were included. Data for the Kaplan-Meier univariate DSS analysis are shown in Table 4.

Univariate analysis of the whole group of 30,906 patients had a 10-year DSS of 76.6\%, a 15-year DSS of $65.4 \%$, and an 18 -year DSS of $59.4 \%$. When analyzed by age group, there was a statistically significant difference $(P<.0001)$ among the 3 groups: those aged less than 60 years $(73 \%$ DSS), those aged 60 to 70 years (61.6\% DSS), and those aged 70 years or more ( $60.8 \%$ DSS) at 15 years. In contrast with the OS results, those aged 6070 years and more than 70 years had similar DSS.
TABLE 2. Analysis of overall survival (\%) by Kaplan-Meier method (univariate)

\begin{tabular}{|c|c|c|c|c|c|c|}
\hline & $\mathbf{n}$ & $\begin{array}{c}\text { At } 5 \\
\mathbf{y} \\
\end{array}$ & $\begin{array}{c}\text { At } 10 \\
\mathbf{y}\end{array}$ & $\begin{array}{c}\text { At } 15 \\
\mathbf{y}\end{array}$ & $\begin{array}{c}\text { At } 18 \\
y\end{array}$ & $\begin{array}{c}P \\
\text { value } \\
\end{array}$ \\
\hline Whole group & 31,206 & 99 & 55.4 & 33.1 & 24.3 & \\
\hline \multicolumn{7}{|l|}{ Age } \\
\hline$<60 \mathrm{y}$ & 9211 & 99.4 & 71.8 & 54.6 & 46 & \\
\hline $60-70 y$ & 12,365 & 98.7 & 55 & 30.6 & 20 & $<.0001$ \\
\hline$>70 y$ & 9630 & 98.6 & 39.6 & 13.6 & 6.5 & \\
\hline \multicolumn{7}{|l|}{ Tumor size } \\
\hline$<3 \mathrm{~cm}$ & 15,091 & 99.1 & 58.2 & 36.3 & 27.4 & $<.0001$ \\
\hline$\geq 3 \mathrm{~cm}$ & 13,631 & 98.8 & 54 & 30.8 & 21.3 & \\
\hline \multicolumn{7}{|l|}{ Sex } \\
\hline Male & 15,118 & 98.9 & 52.7 & 29.7 & 20.7 & $<.0001$ \\
\hline Female & 16,088 & 98.9 & 58.1 & 36.7 & 28.2 & \\
\hline \multicolumn{7}{|l|}{ Site of tumor } \\
\hline 1 (right) & 18,004 & 98.9 & 56.2 & 34.3 & 26.4 & \\
\hline 2 (left) & 12,936 & 98.8 & 54.5 & 31.5 & 21.5 & $<.0001$ \\
\hline $\begin{array}{l}\text { 4, } 9 \text { (bilateral, } \\
\text { paired) }\end{array}$ & 232 & 98.3 & 43.9 & 26.7 & 26.7 & \\
\hline \multicolumn{7}{|l|}{ Histology } \\
\hline Adeno & 15,876 & 98.9 & 56 & 34.4 & 25.3 & \\
\hline Adenosquamous & 716 & 99 & 55 & 30.6 & 22.9 & \\
\hline Large cell & 1980 & 99 & 56.6 & 32.4 & 24.6 & $<.0001$ \\
\hline Other & 2373 & 99.7 & 80.4 & 64.1 & 58.9 & \\
\hline Squamous & 8098 & 98.9 & 49.4 & 24.7 & 15.6 & \\
\hline Unknown & 2163 & 97.5 & 44.6 & 24.7 & 14.9 & \\
\hline \multicolumn{7}{|l|}{ Surgery type } \\
\hline Lobectomy & 21,423 & 99.2 & 59.7 & 36.5 & 26.9 & \\
\hline No surgery & 4679 & 97.6 & 36.9 & 18.1 & 11.2 & $<.0001$ \\
\hline Pneumonectomy & 2203 & 99.1 & 59.5 & 36.4 & 28.7 & \\
\hline Sublobectomy & 2901 & 98.6 & 47.6 & 25.8 & 19.1 & \\
\hline \multicolumn{7}{|l|}{$\mathrm{T}$ stage } \\
\hline $\mathrm{T} 1$ & 12,985 & 99.0 & 58.0 & 36.0 & 26.7 & $<.0001$ \\
\hline $\mathrm{T} 2$ & 14,352 & 98.9 & 54.9 & 32.0 & 23.0 & \\
\hline $\mathrm{T} 3$ & 1157 & 98.4 & 53.0 & 32.0 & 23.2 & \\
\hline $\mathrm{T} 4$ & 2146 & 98.1 & 47.6 & 25.4 & 19.9 & \\
\hline Tunk & 566 & 98.1 & 40.4 & 20.6 & 18.3 & \\
\hline \multicolumn{7}{|l|}{ N stage } \\
\hline No & 23,847 & 99.0 & 57.8 & 35.1 & 26.1 & $<.0001$ \\
\hline N1 & 3178 & 98.8 & 52.1 & 28.7 & 19.7 & \\
\hline $\mathrm{N} 2$ & 2924 & 98.1 & 44.3 & 24.5 & 16.5 & \\
\hline N3 & 415 & 99.0 & 46.6 & 30.1 & 13.4 & \\
\hline Nunk & 842 & 98.0 & 39.8 & 21.6 & 18.1 & \\
\hline \multicolumn{7}{|l|}{ M stage } \\
\hline M0 & 29,709 & 98.9 & 56.1 & 33.5 & 24.6 & $<.0001$ \\
\hline M1 & 1497 & 98.1 & 40.7 & 22.0 & 16.2 & \\
\hline
\end{tabular}

Gender, tumor size, TNM status, and histology were all statistically significant in predicting DSS. The type of surgery performed for curative intent also showed statistical significance $(P<.0001)$ when predicting DSS. At 15 years, patients who received a pneumonectomy had $68.8 \%$ DSS, patients who received a lobectomy had $69.2 \%$ DSS, patients who received a sublobar resection had a $61.0 \%$ DSS, and patients who did not have a surgical procedure for curative intent had a 43.8\% DSS (Figure 2). 
TABLE 3. Analysis of overall survival by Cox proportional hazard model (multivariable regression)

\begin{tabular}{|c|c|c|c|c|c|}
\hline Factor & Parameter estimate & SE & HR & 95\% HR confidence limit & $P$ value \\
\hline Age (per year increase) & 0.044 & 0.001 & 1.045 & (1.043-1.047) & $<.0001$ \\
\hline Sex (male vs female) & 0.154 & 0.018 & 1.166 & $(1.125-1.209)$ & $<.0001$ \\
\hline \multicolumn{6}{|l|}{ Histology } \\
\hline Other vs adeno & -0.704 & 0.049 & 0.494 & $(0.449-0.544)$ & $<.0001$ \\
\hline Adenosquamous vs adeno & 0.006 & 0.059 & 1.006 & $(0.896-1.129)$ & .921 \\
\hline Large cell vs adeo & -0.065 & 0.036 & 0.938 & $(0.873-1.007)$ & .077 \\
\hline Squamous vs adeno & 0.079 & 0.021 & 1.082 & $(1.038-1.128)$ & .0002 \\
\hline Unknown vs adeno & -0.01 & 0.039 & 0.991 & $(0.918-1.069)$ & .808 \\
\hline \multicolumn{6}{|l|}{ Surgery type } \\
\hline Pneumonectomy vs no surgery & -0.58 & 0.046 & 0.560 & $(0.511-0.613)$ & $<.0001$ \\
\hline Sublobectomy vs no surgery & -0.235 & 0.041 & 0.791 & $(0.730-0.856)$ & $<.0001$ \\
\hline Lobectomy vs no surgery & 0.558 & 0.032 & 0.572 & $(0.537-0.610)$ & $<.0001$ \\
\hline \multicolumn{6}{|l|}{ Site of tumor } \\
\hline 4, 9 (bilateral, paired) vs right & 0.021 & 0.018 & 1.022 & $(0.986-1.058)$ & .235 \\
\hline Left vs right & -0.202 & 0.110 & 0.817 & $(0.658-1.014)$ & .067 \\
\hline \multicolumn{6}{|l|}{ T stage } \\
\hline $\mathrm{T} 2$ vs $\mathrm{T} 1$ & 0.053 & 0.020 & 1.055 & (1.015-1.096) & .007 \\
\hline $\mathrm{T} 3$ vs $\mathrm{T} 1$ & 0.115 & 0.049 & 1.122 & (1.020-1.234) & .018 \\
\hline T4 vs T1 & 0.096 & 0.040 & 1.101 & (1.017-1.192) & .018 \\
\hline Tunk vs T1 & -0.025 & 0.082 & 0.975 & $(0.830-1.146)$ & .760 \\
\hline \multicolumn{6}{|l|}{$\mathrm{N}$ stage } \\
\hline N1 vs N0 & 0.282 & 0.029 & 1.325 & $(1.252-1.404)$ & $<.0001$ \\
\hline N2 vs N0 & 0.226 & 0.034 & 1.254 & (1.173-1.340) & $<.0001$ \\
\hline N3 vs N0 & 0.110 & 0.084 & 1.116 & $(0.947-1.316)$ & .189 \\
\hline Nunk vs N0 & -0.007 & 0.062 & 0.993 & $(0.879-1.122)$ & .912 \\
\hline \multicolumn{6}{|l|}{ M stage } \\
\hline M1 vs M0 & 0.188 & 0.052 & 1.207 & (1.089-1.337) & .0003 \\
\hline \multicolumn{6}{|l|}{ Race } \\
\hline Black vs white & 0.093 & 0.031 & 1.097 & (1.032-1.167) & .003 \\
\hline Other vs white & -0.213 & 0.039 & 0.808 & $(0.749-0.873)$ & $<.0001$ \\
\hline
\end{tabular}

$S E$, Standard error; $H R$, hazard ratio.

Table 5 shows the results of multivariable competing risk model for DSS. The disease-specific HR for each additional year of age was $1.021(P<.0001)$. Male gender and adenocarcinoma histology had worse DSS. Left-sided tumors had a statistically significant DSS advantage compared with right-sided tumors (HR, 0.723; $P=.036$ ). When compared with not receiving surgery for curative intent, multivariable analysis showed a DSS benefit for pneumonectomy (HR, 0.440), lobectomy (HR, 0.474), and sublobectomy (HR, 0.710) (all $P<.0001$ ).

Advanced tumor stages (T2, T3, T4) showed significantly worse DSS compared with T1 stage tumors. Node-positive patients showed significantly worse DSS than nodenegative patients (N1 vs N0, HR 1.607; N2 vs N0, HR 1.464; and N3 vs N0, HR 1.339). Moreover, the differences in survival between each nodal stage was statistically significant (N1 vs N2, N2 vs N3, and N1 vs N3, all $P<.0001$ ). When a separate multivariable analysis was performed grouping all nodal patients together as node positive (N1 or N2 or N3) and comparing with N0 patients, the HR was 1.293 for OS $(P<.0001)$ and 1.538 for DSS $(P<.0001)$.

\section{DISCUSSION}

This SEER review of 5-year NSCLC survivors reveals that 5-year survival does not equal cure from lung cancer and that approximately half of the deaths in 5-year survivors are categorized as due to lung cancer.

There are several important limitations to this study. First, although the SEER database is broad, the accuracy of the submitted data is dependent on submissions by individual practitioners. ${ }^{12}$ The categorization of cause of death as lung cancer or non-lung cancer-related may not always be clear. Death from neutropenic infection related to a chemotherapy treatment would most likely be categorized as lung cancer related. Death from pneumonia 6 years after pneumonectomy would likely not be attributed to lung cancer, although it depends on the judgment of the individual filling out the death certificate. Second, the SEER database does not contain data regarding chemotherapy, and radiation data were excluded from the analysis because it was complete for only $10 \%$ of patients. Third, DSS in the SEER database does not distinguish between death from the original tumor and death from a new, separate lung primary. It has been estimated that patients with 
TABLE 4. Analysis of disease-specific survival (\%) by Kaplan-Meier method (univariate)

\begin{tabular}{|c|c|c|c|c|c|c|}
\hline & $\mathbf{n}$ & At $5 y$ & At $10 y$ & At $15 y$ & At $18 y$ & $\begin{array}{c}P \\
\text { value }\end{array}$ \\
\hline Whole group & 30,906 & 99.3 & 76.6 & 65.4 & 59.4 & \\
\hline \multicolumn{7}{|l|}{ Age } \\
\hline$<60 \mathrm{y}$ & 9136 & 99.6 & 82.2 & 73 & 67.9 & \multirow{3}{*}{$<.0001$} \\
\hline $60-70 y$ & 12,232 & 99.2 & 74.8 & 61.6 & 54.2 & \\
\hline$>70 y$ & 9538 & 99.3 & 72.7 & 60.8 & 54.9 & \\
\hline \multicolumn{7}{|l|}{ Tumor size } \\
\hline$<3 \mathrm{~cm}$ & 14,963 & 99.5 & 79.2 & 69.2 & 63.8 & \multirow[t]{2}{*}{$<.0001$} \\
\hline$\geq 3 \mathrm{~cm}$ & 13,493 & 99.2 & 75.2 & 62.5 & 55.5 & \\
\hline \multicolumn{7}{|l|}{$\operatorname{Sex}$} \\
\hline Male & 14,962 & 99.4 & 75.8 & 64 & 57.8 & \multirow[t]{2}{*}{.0005} \\
\hline Female & 15,944 & 99.3 & 77.4 & 66.7 & 61 & \\
\hline \multicolumn{7}{|l|}{ Site of tumor } \\
\hline 1 (right) & 17,835 & 99.4 & 77 & 66 & 60.3 & \multirow{3}{*}{.01} \\
\hline 2 (left) & 12,807 & 99.3 & 76.2 & 64.6 & 58.2 & \\
\hline $\begin{array}{l}\text { 4, } 9 \text { (bilateral, } \\
\text { paired) }\end{array}$ & 230 & 99.1 & 66.9 & 58.7 & & \\
\hline \multicolumn{7}{|l|}{ Histology } \\
\hline Adeno & 15,723 & 99.3 & 74.9 & 63.7 & 56.5 & \multirow{6}{*}{$<.0001$} \\
\hline Adenosquamous & 709 & 99.7 & 77.8 & 62.9 & 62.9 & \\
\hline Large cell & 1953 & 99.4 & 77 & 63.4 & 57.9 & \\
\hline Other & 2361 & 99.9 & 95 & 92.4 & 91.9 & \\
\hline Squamous & 8020 & 99.5 & 75.6 & 61.9 & 55.7 & \\
\hline Unknown & 2140 & 98.4 & 69.1 & 57.6 & 51.3 & \\
\hline \multicolumn{7}{|l|}{ Surgery type } \\
\hline Lobectomy & 21,227 & 99.5 & 80.2 & 69.2 & 63.4 & \multirow{4}{*}{$<.0001$} \\
\hline No surgery & 4611 & 98.5 & 58.3 & 43.8 & 35.7 & \\
\hline Pneumonectomy & 2191 & 99.5 & 79.7 & 68.8 & 64.3 & \\
\hline Sublobectomy & 2877 & 99.4 & 72 & 61 & 52.7 & \\
\hline \multicolumn{7}{|l|}{ T stage } \\
\hline $\mathrm{T} 1$ & 12,880 & 99.5 & 79.3 & 69.3 & 63.0 & \multirow[t]{5}{*}{$<.0001$} \\
\hline $\mathrm{T} 2$ & 14,198 & 99.3 & 76.4 & 64.5 & 58.4 & \\
\hline $\mathrm{T} 3$ & 1145 & 99.1 & 71.4 & 59.4 & 58.1 & \\
\hline $\mathrm{T} 4$ & 2125 & 98.7 & 67.1 & 53.6 & 46.4 & \\
\hline Tunk & 558 & 98.6 & 62.5 & 45.1 & & \\
\hline \multicolumn{7}{|l|}{$\mathrm{N}$ stage } \\
\hline No & 23,627 & 99.0 & 79.7 & 68.9 & 63.1 & \multirow[t]{5}{*}{$<.0001$} \\
\hline N1 & 3153 & 99.0 & 70.9 & 58.8 & 52.5 & \\
\hline $\mathrm{N} 2$ & 2880 & 98.6 & 62.2 & 50.4 & 40.7 & \\
\hline N3 & 414 & 99.5 & 62.9 & 50.5 & 44.9 & \\
\hline Nunk & 832 & 98.9 & 62.7 & 43.7 & 40.3 & \\
\hline \multicolumn{7}{|l|}{ M stage } \\
\hline M0 & 29,425 & 99.4 & 77.3 & 66.2 & 60.1 & \multirow[t]{2}{*}{$<.0001$} \\
\hline M1 & 1481 & 98.6 & 60.1 & 45.2 & 41.4 & \\
\hline
\end{tabular}

resected early lung cancers have a $1 \%$ to $2 \%$ chance per year of developing a new lung cancer. ${ }^{13}$ This means that individuals alive 15 years after diagnosis have a cumulative $22.5 \%$ chance of developing a second primary lung cancer. Although many of these new lung cancers are discovered early, this could negatively affect the long-term survival. A recent publication regarding curative resections for stage I NSCLC details an early hazard of recurrence in the first 2 years and a low level of constant recurrence up to 14 years after resection that may represent metachronous primary cancers. ${ }^{14}$

Nodal stage had a significant impact on both OS and DSS, but in a nonlinear manner, with the worst HRs seen in patients with $\mathrm{N} 1$ disease (Tables 3 and 5). Patients with $\mathrm{N} 2$ and $\mathrm{N} 3$ disease had progressively better OS and DSS. The reasons for this are not clear but may reflect the high degree of pathologic confirmation of $\mathrm{N} 1$ disease (typically determined at operation only) as opposed to the relatively more common non-pathologic determination of N2 or N3 (supraclavicular or contralateral tracheal) nodal disease. Beyond 5 years, N2 and N3 disease do not seem to carry the same negative prognostic survival value as they do at 5 years. Nodal positivity continues to affect the likelihood of death 10,15, and 18 years after initial diagnosis and treatment. Tumor stage also had a significant impact on both OS and DSS, although no significant differences were necessarily seen between tumor stages above T1.

Tumor histology had a significant impact on long-term survival. The category labeled as "other" in the SEER database had an HR of $0.494(P<.0001)$ for OS and 0.250 $(P<.0001)$ for DSS. Although not specifically analyzed in this study, a large number of these cancers were undoubtedly carcinoid tumors. In a prior study limited by small sample size, Wada and colleagues ${ }^{3}$ demonstrated significance for age, $\mathrm{N}$-stage, and complete versus incomplete surgical resections in predicting survival after 5 years, but they did not find a significant difference between adenocarcinoma compared with squamous cell carcinomas. ${ }^{5}$ The Lung Cancer Study Group published a report that a disease-free survival advantage was seen with squamous cell carcinomas up to 5 years after surgery, but no survival advantage was seen after 5 years. ${ }^{15}$ Again, there was a small sample size of only 21 patients who were alive after 5 years. In our study, squamous cell cancers had a highly statistically significant negative effect on overall long-term survival relative to adenocarcinoma (HR, 1.082; $P=.0002$ ) but a statistically significant positive effect on long-term DSS (HR, 0.877; $P=.0001$ ). This may be related to a higher associated incidence of comorbid disease in those with squamous cell cancer because this specific histologic subtype of NSCLS is more frequently associated with a history of smoking. The improved DSS of squamous cell carcinoma may indicate an inherently lower risk of metastatic spread compared with adenocarcinoma.

Age had an effect on both OS (HR, 1.045; $P<.0001)$ and DSS (HR, 1.021; $P<.0001)$. There is an approximately $5 \%$ increased risk of death for every increase in year of age in regard to OS, whereas there is a $2 \%$ increased risk of death from lung cancer for every increase in year of age after surviving 5 years from the initial diagnosis of NSCLC. Increasing age may influence the ability of an individual to survive complications of lung cancer, thus influencing DSS. Male 


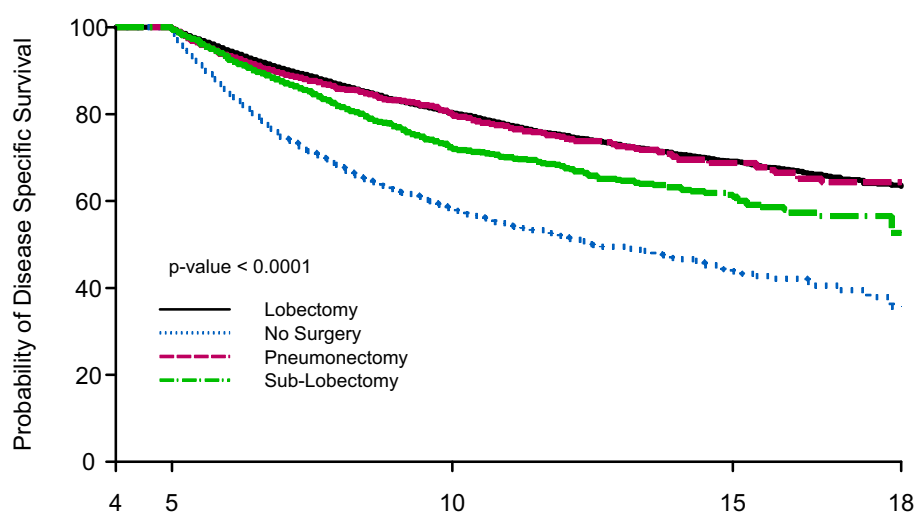

Years after Diagnosis

$\begin{array}{ccccc}\text { No.at Risk:Lobectomy } & 21227 & 6466 & 1367 & 231 \\ \text { No.at Risk:No Surgery } & 4611 & 650 & 87 & 15 \\ \text { No.at Risk:Pneumonectomy } & 2191 & 615 & 154 & 30 \\ \text { No.at Risk:Sub-Lobectomy } & 2877 & 676 & 137 & 25\end{array}$

FIGURE 2. Graphs of 5- to 18-year DSS by surgery type. Survival is best in patients undergoing lobectomy or pneumonectomy.

gender had a similar negative effect on OS (HR, 1.166; $P<.0001)$, but the DSS difference did not reach statistical significance (HR, 1.054; $P=.053)$.
Pneumonectomy and lobectomy carry a significant advantage in regard to both prolonged OS and DSS. Comorbidities are not measured in the SEER database and can

TABLE 5. Analysis of disease-specific survival by competing risks Cox proportional hazards model (multivariable regression)

\begin{tabular}{|c|c|c|c|c|c|}
\hline Factor & Parameter estimate & SE & HR & 95 $\%$ HR confidence limit & $P$ value \\
\hline Age (per year increase) & 0.020 & 0.001 & 1.021 & $(1.018-1.023)$ & $<.0001$ \\
\hline Sex (male vs female) & 0.053 & 0.027 & 1.054 & $(0.999-1.113)$ & .053 \\
\hline \multicolumn{6}{|l|}{ Histology } \\
\hline Other vs adeno & -1.587 & 0.104 & 0.205 & $(0.167-0.251)$ & $<.0001$ \\
\hline Adenosquamous vs adeno & -0.136 & 0.092 & 0.873 & $(0.729-1.045)$ & .139 \\
\hline Large cell vs adeno & -0.215 & 0.054 & 0.807 & $(0.725-0.898)$ & $<.0001$ \\
\hline Squamous vs adeno & -0.132 & 0.033 & 0.877 & $(0.822-0.935)$ & $<.0001$ \\
\hline Unknown vs adeno & -0.234 & 0.057 & 0.791 & $(0.708-0.885)$ & $<.0001$ \\
\hline \multicolumn{6}{|l|}{ Surgery type } \\
\hline Pneumonectomy vs no surgery & -0.821 & 0.068 & 0.440 & $(0.385-0.503)$ & $<.0001$ \\
\hline Sublobectomy vs no surgery & -0.342 & 0.060 & 0.710 & $(0.631-0.799)$ & $<.0001$ \\
\hline Lobectomy vs no surgery & -0.746 & 0.046 & 0.474 & $(0.433-0.519)$ & $<.0001$ \\
\hline \multicolumn{6}{|l|}{ Site of tumor } \\
\hline 4, 9 (bilateral, paired) vs right & 0.028 & 0.027 & 1.028 & $(0.975-1.085)$ & .305 \\
\hline Left vs right & -0.325 & 0.155 & 0.723 & $(0.534-0.979)$ & .036 \\
\hline \multicolumn{6}{|l|}{ T stage } \\
\hline $\mathrm{T} 2$ vs $\mathrm{T} 1$ & 0.106 & 0.030 & 1.111 & $(1.047-1.180)$ & .0005 \\
\hline $\mathrm{T} 3$ vs T1 & 0.255 & 0.069 & 1.290 & $(1.127-1.476)$ & .0002 \\
\hline $\mathrm{T} 4$ vs $\mathrm{T} 1$ & 0.2 & 0.057 & 1.221 & $(1.092-1.366)$ & .0005 \\
\hline Tunk vs T1 & -0.005 & 0.107 & 0.995 & $(0.806-1.227)$ & .96 \\
\hline \multicolumn{6}{|l|}{$\mathrm{N}$ stage } \\
\hline N1 vs N0 & 0.474 & 0.042 & 1.607 & $(1.480-1.744)$ & $<.0001$ \\
\hline $\mathrm{N} 2$ vs N0 & 0.381 & 0.047 & 1.464 & $(1.335-1.606)$ & $<.0001$ \\
\hline N3 vs N0 & 0.292 & 0.104 & 1.339 & $(1.092-1.640)$ & .005 \\
\hline Nunk vs N0 & 0.084 & 0.084 & 1.088 & $(0.923-1.283)$ & .316 \\
\hline \multicolumn{6}{|l|}{ M stage } \\
\hline M1 vs M0 & 0.313 & 0.069 & 1.367 & (1.195-1.564) & $<.0001$ \\
\hline \multicolumn{6}{|l|}{ Race } \\
\hline Black vs white & 0.106 & 0.046 & 1.112 & $(1.017-1.216)$ & .020 \\
\hline Other vs white & -0.079 & 0.055 & 0.924 & $(0.830-1.028)$ & .148 \\
\hline
\end{tabular}

$S E$, Standard error; $H R$, hazard ratio. 
influence OS and perhaps, to a lesser degree, DSS. Patients with borderline lung function or other significant comorbidities are often preferentially offered lesser resections than fit patients, and this may confound these findings. The persistence and magnitude of the survival benefit in DSS for lobar and greater surgical resection compared with sublobar resection suggest that factors other than comorbidities may account for this advantage. In the absence of a prospective randomized trial, definitive conclusions cannot be made in regard to the effect of magnitude of resection on longterm survival. In one of the few such trials conducted to date, the Lung Cancer Study Group showed no statistically significant difference in 5-year survival for stage I lung cancers treated with lobectomy versus sublobar resection. ${ }^{16}$

The finding that a left-sided cancer conferred a $38 \%$ better disease-free long-term survival has not been described in regard to long-term survival. It is well established that rightsided pneumonectomy has a slightly higher mortality than left-sided pneumonectomy. ${ }^{17}$ In regard to long-term survival, it is conceivable that patients who have had larger lung resections (in right vs left pneumonectomy, the right lung typically contributes $60 \%$ of total lung function) may be at higher risk of late pneumonia and respiratory death. Only $7 \%$ of patients in this study underwent pneumonectomy.

\section{CONCLUSIONS}

The finding that many patients die of lung cancer well beyond the point at which many clinicians have considered these patients "cured" (ie, 5 years) has not only obvious implications for prognosis but also implications in regard to treatment and clinical trial design. The concept of maintenance chemotherapy for NSCLC is being explored as newer, less toxic agents are developed. ${ }^{18}$ The finding that lung cancer deaths occur far beyond 5 years suggests that there may be significant benefit for long-term survivors if such an agent can be found. In addition, it has recently become apparent, as a result of long-term follow-up after adjuvant chemotherapy for resected NSCLC, that there may be a loss in the survival benefit of chemotherapy with prolonged survival. ${ }^{19}$ In the long-term follow up (median 90 months) publication of the International Adjuvant Lung Cancer Trial, the survival benefit to adjuvant chemotherapy was lost in delayed follow-up. The HR for death after chemotherapy was $0.86(P=.01)$ for the first 5 years, but 1.45 $(P=.04)$ after 5 years. There is concern that some of these late deaths may be from delayed chemotoxicity. A certain percentage of these deaths, however, may likely be delayed cancer deaths that are seen even without chemotherapy. This evolving concept that a significant number of cancer deaths occur well beyond 5 years should be incorporated into future trials.

The authors thank Julie Worthington, $\mathrm{PhD}$, for statistical analyses and contributions to the article.

\section{References}

1. American Cancer Society. Cancer Facts \& Figures 2010. Atlanta, GA: American Cancer Society; 2010.

2. Horner MJ, Ries LAG, Krapcho M. SEER Cancer Statistics Review, 1975-2006. Bethesda, MD: National Cancer Institute. Based on November 2008 SEER data submission, posted to the SEER web site, 2009. Available at: http://seer.cancer. gov/csr/1975_2006/. Accessed January 31, 2012.

3. Wada H, Fukuse T, Hitomi S. Long-term survival of surgical cases of lung cancer. Lung Cancer. 1995;13:269-74.

4. Temeck BK, Flehinger BJ, Martini N. A retrospective analysis of 10-year survivors from carcinoma of the lung. Cancer. 1984;53:1405-8.

5. International Early Lung Cancer Action Program Investigators Henschke CI, Yankelevitz DF, Libby DM, Pasmantier MW, Smith JP, Miettinen OS. Survival of patients with stage I lung cancer detected on CT screening. N Engl J Med. 2006;355:1763-71

6. Martini N, Rusch VW, Bains MS, Kris MG, Downey RJ, Ginsberg RJ, et al. Factors influencing ten-year survival in resected stages I to IIIA non-small cell lung cancer. J Thorac Cardiovasc Surg. 1999;117:32-8.

7. World Health Organization. International Classification of Diseases for Oncology. 2nd ed. Geneva, Switzerland: World Health Organization; 1990.

8. World Health Organization. International Statistical Classification of Diseases and Related Health Problems Tenth Revision, Volume 2. 2nd ed. Geneva, Switzerland: World Health Organization; 2004.

9. Cox DR. Regression models and life-tables. J Royal Stat Soc B. 1972;34: 187-220.

10. Kalbfleisch JD. Chapter 8: Competing risks and multistate models. In: Kalbfleisch JD, Prentice RL, eds. The Statistical Analysis of Failure Time Data. 2nd ed. Hoboken, NJ: John Wiley \& Sons; 2002:247.

11. Pepe MS, Mori M. Kaplan-Meier, marginal or conditional-probability curves in summarizing competing risks failure time data. Stat Med. 1993;12:737-51.

12. Zippin C, Lum D, Hankey BF. Completeness of hospital cancer case reporting from the SEER Program of the National Cancer Institute. Cancer. 1995;76: 2343-50.

13. Johnson BE. Second lung cancers in patients after treatment for an initial lung cancer. J Natl Cancer Inst. 1998;90:1335-45

14. Murthy SC, Reznick SI, Ogwudu UC, Farver CF, Arrossi A, Blackstone EH, et al Winning the battle, losing the war: the noncurative "curative" resection for stage I adenocarcinoma of the lung. Ann Thorac Surg. 2010;90:1067-74.

15. Thomas P, Rubinstein L, Lung Cancer Study Group. Cancer recurrence after resection: T1N0 non-small lung cancer. Ann Thorac Surg. 1990;49:242-7.

16. Ginsberg RJ, Rubinstein LV. Randomized trial of lobectomy versus limited resection for T1 N0 non-small cell lung cancer. Lung Cancer Study Group. Ann Thorac Surg. 1995;60:615-23.

17. van Meerbeeck JP, Damhuis RA, Vos de Wael ML. High postoperative risk after pneumonectomy in elderly patients with right-sided lung cancer. Eur Respir J. 2002;19:141-5.

18. Owonikoko TK, Ramalingam SS, Bealni CP. Maintenance therapy for advanced non small cell lung cancer: current status, controversies, and emerging consensus. Clin Cancer Res. 2010;16:2496-504.

19. Arriagad R, Dunant A, Pignon J, Bergman B, Chabowki M, Grunenwald D, et al Long-term results of the international adjuvnat lung cancer trial evaluating adjuvant cisplatin based chemotherapy in resected lung cancer. J Clin Oncol. 2010; 28:35-42. 